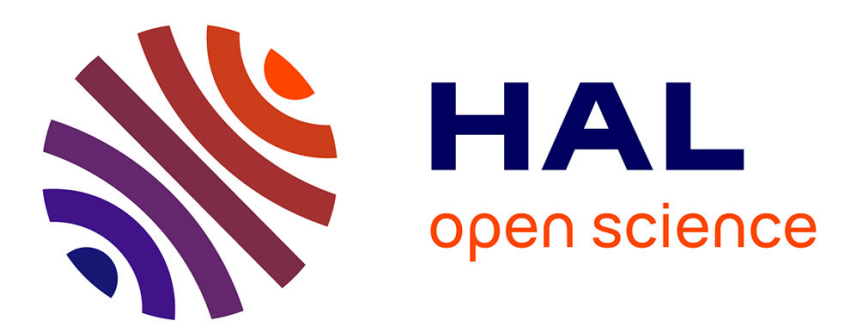

\title{
Cyclostationarity-based Estimation of the Foetus Subspace Dimension From ECG Recordings
}

Michel Haritopoulos, Julien Roussel, Cécile Capdessus, A.K. Nandi

\section{To cite this version:}

Michel Haritopoulos, Julien Roussel, Cécile Capdessus, A.K. Nandi. Cyclostationarity-based Estimation of the Foetus Subspace Dimension From ECG Recordings. XIII Mediterranean Conference on Medeical and Biological Engineering and Computing, Sep 2013, Sevilla, Spain. to be published. hal-00839176v2

\section{HAL Id: hal-00839176 \\ https://hal.science/hal-00839176v2}

Submitted on 24 Jul 2013

HAL is a multi-disciplinary open access archive for the deposit and dissemination of scientific research documents, whether they are published or not. The documents may come from teaching and research institutions in France or abroad, or from public or private research centers.
L'archive ouverte pluridisciplinaire HAL, est destinée au dépôt et à la diffusion de documents scientifiques de niveau recherche, publiés ou non, émanant des établissements d'enseignement et de recherche français ou étrangers, des laboratoires publics ou privés. 


\title{
CYCLOSTATIONARITY-BASED ESTIMATION OF THE FOETUS SUBSPACE DIMENSION FROM ECG RECORDINGS
}

\author{
M. Haritopoulos ${ }^{1}$, J. Roussel ${ }^{1}$, C. Capdessus ${ }^{1}$ and A.K. Nandi ${ }^{2}$ \\ ${ }^{1}$ PRISME Laboratory, 21 rue de Loigny La Bataille, Chartres, France \\ ${ }^{2}$ Department of Electronic and Computer Engineering, Brunel University, Uxbridge, Middlesex, UK
}

\begin{abstract}
In this work, a novel method based on the cyclostationary properties of electrocardiogram (ECG) signals is introduced in order to classify independent subspaces into components reflecting the electrical activity of the foetal heart and those corresponding to mother's heartbeats, while the remaining ones are mainly due to noise. This research is inspired from multidimensional independent component analysis (MICA), a method that aims at grouping together into independent multidimensional components blind source separated signals from a set of observations. Given an input set of observations, independent component analysis (ICA) algorithms estimate the latent source signals which are mixed together. In the case of ECG recordings from the maternal thoracic and abdominal areas, the foetal ECGs (FECGs) are contaminated with maternal ECGs (MECG), electronic noise, and various artifacts (respiration, for example). When ICA-based methods are applied to these measurements, many of the output estimated sources have the same physiological origin: the mother's or the foetus' heartbeats. Thereby, we show that a procedure for automatic classification in independent subspaces of the extracted FECG and MECG components is feasible when using a criterion based on the cyclic coherence (CC) of the signal of interest.
\end{abstract}

Keywords - foetal electrocardiogram, cyclostationarity, cyclic coherence, multidimensional independent component analysis

\section{INTRODUCTION}

Electrocardiogram (ECG) is one of the most popular diagnostic tools for heart monitoring. Non-invasive electrical activity measurement devices, like electrodes, offer clinicians a versatile tool, without heavy constraints, for preventing complications or diseases due to heart defects. When these measurements come from the thoracic or abdominal regions of a pregnant woman, detecting and separating the foetal electrocardiogram (FECG) from the maternal one (MECG) is not such an easy task, since the FECG has a very low amplitude voltage signal compared to the MECG, and, moreover, the activity measured by the cutaneous electrodes is disturbed by other noise signals, such as random instrumentation noise, power line signal, breathing or baseline wandering.

In these last decades, various signal processing techniques have emerged and many of them have been customized for FECG extraction purposes ([1], [2], [3]). Among them are blind source separation (BSS) techniques [4] and the underlying mathematical tool which is independent component analysis (ICA). It aims at separating unknown source signals of interest from a mixture of them, observed with the aid of sensors. Numerous methods can be found in the dedicated literature, but only a few make use of the concept of multidimensional independent component analysis (MICA), introduced in the late 90's. Interested readers can find a recent review on FECG signal processing in [5].

In the rest of the paper, we first present the MICA concept. An introduction to the cyclostationary nature of ECGs and a description of a cyclostationarity measure, called cyclic coherence, follows. Next, a novel FECG classification procedure is proposed and validated on a real world FECG dataset; it is based on the cyclic coherence computation of the ICA estimated components from a set of sensor signals. Finally, conclusions are drawn from this work.

\section{ICA AND THE MULTIDIMENSIONAL ICA (MICA) CONCEPT}

\section{A. Blind source separation problem formulation and ICA}

Jutten et al first proposed a simple $2 \times 2$ neural networkbased self-adaptive algorithm ([6], [7]) as a solution to the separation of independent source signals, and introduced the concept of independent component analysis, which has been theoretically investigated few years later by Comon [8]. The problem in blind source separation (BSS) states as follows: given a set of $M$ observed signals $x_{i}(t), i \in[1, M]$, find the $N$ unknown sources $s_{i}(t), i \in[1, N]$, with $N \leq M$, that are hidden in the observations. In matrix form, the problem writes:

$$
\mathbf{x}(t)=A \mathbf{s}(t) .
$$

where $\mathbf{x}(t)=\left[x_{1}(t), x_{2}(t), \ldots, x_{M}(t)\right]^{\dagger}$ and $\mathbf{s}(t)=$ $\left[s_{1}(t), s_{2}(t), \ldots, s_{N}(t)\right]^{\dagger}$ denote the mixture vector and 
the unknown source vector, respectively, with $\dagger$ the transpose operator and with $\mathrm{A}$ an unknown $M \times N$ full rank mixing matrix. The mixture model of eq. 1 is the linear instantaneous noiseless one, which is widely used in the literature and which only assumes statistically independent source components $s_{i}$ and at most one Gaussian entry.

\section{B. Multidimensional ICA}

A source subspace separation method for FECG extraction has been presented in [9]. In this work, authors use secondorder statistics based on the singular value decomposition (SVD) of the observed ECG data matrix to estimate the underlying source subspaces, assuming that the latent bioelectric phenomena generating the foetal and the mother heartbeats are statistically independent. Then, they enhance the accuracy of the proposed algorithm by introducing a higherorder singular value decomposition (HOSVD) technique.

A similar technique is proposed by Cardoso in [10] named multidimensional independent component analysis (MICA). It can be seen as a generalization of the ICA model to multidimensional components. The author illustrates his method with real FECG data. First, he estimates the unknown sources by applying the well known ICA algorithm JADE [11] to a 3-channel real ECG data of an expectant mother. After extraction of the independent components (ICs), he groups two of them into a bi-dimensional component corresponding to the MECG; the choice of these two components is done only after visual inspection and, in this case, that works because mother's and foetus' contributions are clearly distinguishable. After computing the orthogonal projection matrices for each one of the two estimated multidimensional components, a back-projection to the original input space permits to reconstruct the mother and foetal signal contributions to the mixtures.

We demonstrate below how to establish an automated procedure based on the cyclostationary properties of the ECG signals, in order to classify ICA-based extracted ICs into multidimensional components.

\section{CYCLOSTATIONARITY MEASURES}

\section{A. The cyclostationarity property}

The main assumption for this procedure to succeed, is that the foetus' as well as the mother's heartbeats, if they do not exhibit a strict period, they are at least repetitive, i.e. cyclostationary at the frequency $\alpha_{0}$ of the heartbeats. A cyclostationary signal is not strictly periodic, but some of its statistical properties are periodic. This same assumption of FECG cyclostationarity used in previous work [12], together with the a priori estimation of the foetus' fundamental cyclic frequency, provided very promising results with regard to the foetal PQRST extraction.

In this context, we use a statistical measure of cyclostationarity as a criterion to decide whether an ICA estimated IC corresponds to the FECG rather than to the MECG subspace. This measure is the cyclic coherence.

\section{B. The cyclic coherence measure}

In this work, we use a spectral version of the simple coherence [13] which is a measure of the correlation degree between two signals, $x(t)$ and $y(t)$, at each frequency value $f$. It is called the cyclic coherence (CC) and it has been introduced in [14]:

$$
C_{x}^{\alpha}(f)=\frac{E\left[X(f) X^{*}(f-\alpha)\right]}{\left(E\left[\mid X\left(\left.f\right|^{2}\right] E\left[|X(f-\alpha)|^{2}\right]\right)^{\frac{1}{2}}\right.},
$$

where $X(f)$ and $X(f-\alpha)$ are the Fourier Transforms of $x(t)$ and alpha value frequency-shifted $x(t)$, respectively.

The CC measure is normalised. A CC value near to one for a frequency $f$, indicates a strong coherence between components of signal $x(t)$ at frequencies $f$ and $(f-\alpha)$.

\section{THE PROPOSED METHOD AND ILLUSTRATION WITH REAL WORLD DATA}

To illustrate the proposed method, we worked on the same dataset as in the original MICA work [10], i.e. the wellknown DaISy database [15], but we considered the whole recordings set. This is an eight-channel cutaneous recordings set from an expectant mother. The first five potentials come from electrodes placed at different locations in the abdominal region of the mother, while the last three recordings come from her thoracic region. All eight signals are recorded simultaneously at a sampling rate of $500 \mathrm{~Hz}$ and each one of them lasts $5 \mathrm{sec}$ (Figure 1).

\section{A. The classification procedure}

We first applied the JADE algorithm to the whole observations vector and then we computed the CCs of the estimated components. A visual inspection of the obtained CCs leads to a preliminary classification of extracted components $\{3,5\}$ into the FECG subspace, components $\{1,4\}$ into the noise subspace and the remaining components $\{2,6,7,8\}$ into the MECG subspace (Figures 2, 3 and 4, respectively). Indeed, in 


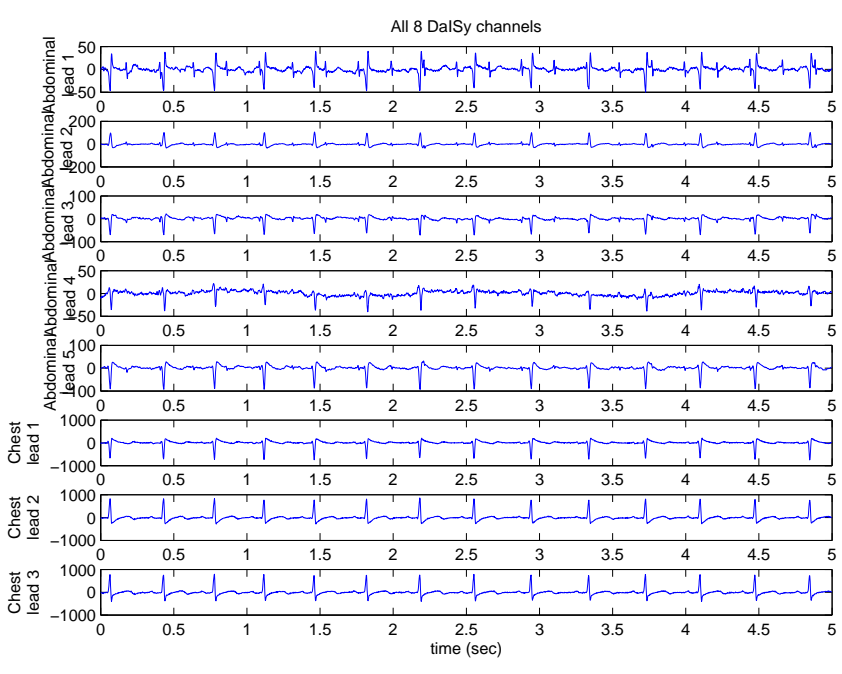

Fig. 1: Eight surface electrodes recordings

Figure 2 one clearly notices the high values over all the spectral frequencies range, for cyclic frequency around $4.5 \mathrm{~Hz}$ that corresponds to the fundamental cyclic frequency of the foetus' heart [12], while the second high-valued spectral line corresponds to its second harmonics. On the contrary, no $(f, \alpha)$ couple has a significantly high value in the CCs of JADE extracted components 1 and 4, as one can observe in Figure 3. This is in agreement with the kurtosis values of these two CCs: 4.94 and 0.54, for components 1 and 4, respectively. Lower kurtosis values may correspond to noisy background.

CCs of JADE estimated components 3 (left) and 5 (right)
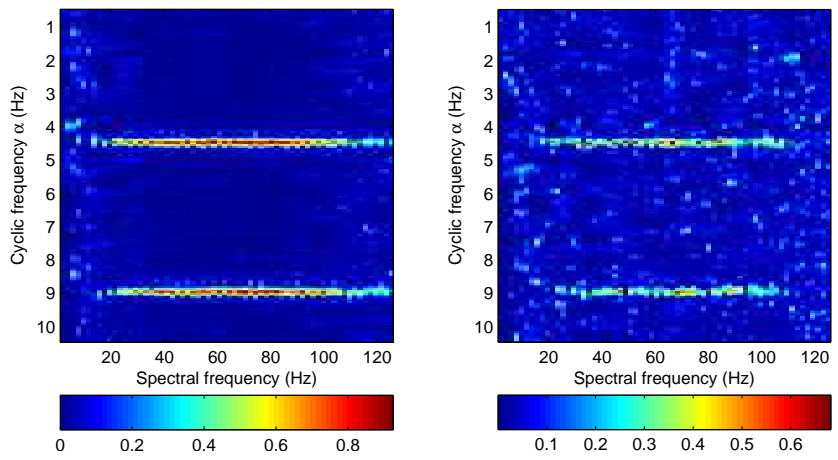

Fig. 2: The 2-dimensional FECG subspace

Things get a little bit different for the MECG subspace. CCs of JADE estimates 2, 6 and 8 exhibit distinct higher values for cyclic frequency around $2.7 \mathrm{~Hz}$ into the spectral frequency range $[20,80] \mathrm{Hz}$ (Figure 4); all three span the subspace of the MECG components. On the other hand, the CC
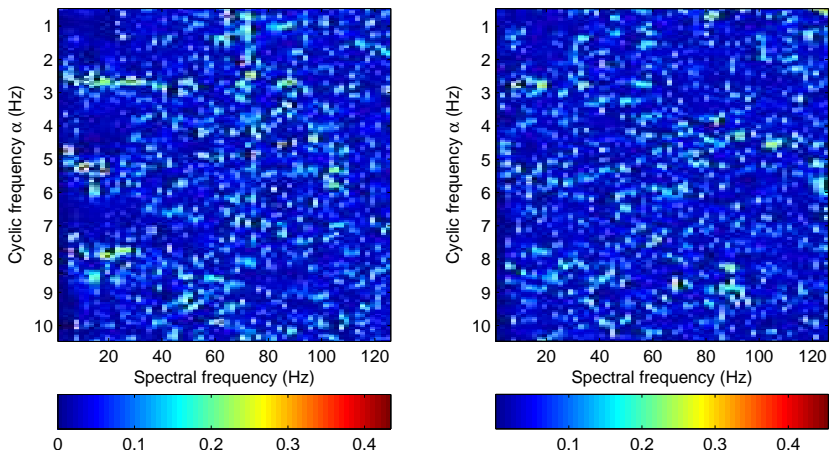

Fig. 3: The 2-dimensional noise subspace

of the JADE estimated component number 7, shows also high values for cyclic frequencies different from the mother's fundamental one and its harmonics. That needs more investigations to interpret, but it is not decisive for the classification procedure of foetal components that this work suggests.

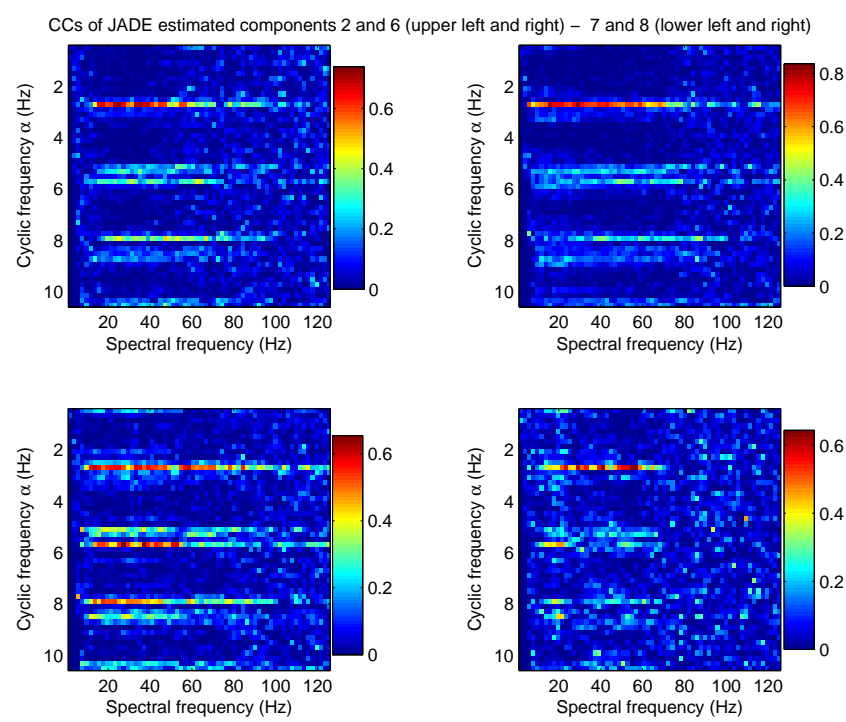

Fig. 4: The 4-dimensional MECG subspace

Next, we integrate the cyclic frequencies for each $\mathrm{CC}$ of the ICA estimated components over the spectral frequencies to obtain the integrated $\mathrm{CC}$ (iCC). At this stage to automate the extraction of the noise subspace components, one can compute the standard deviation of each iCC; standard deviation values for this example are $\{0.68 ; 3.59 ; 5.29 ; 0.69 ; 2.41 ; 4.20 ; 4.44 ; 1.92\}$ for the $1^{s t}$ through to the $8^{\text {th }}$ JADE extracted IC. Looking for standard deviation values below a low-valued threshold, is an efficient 
way for isolating ICs whose iCCs do not contain significant information.

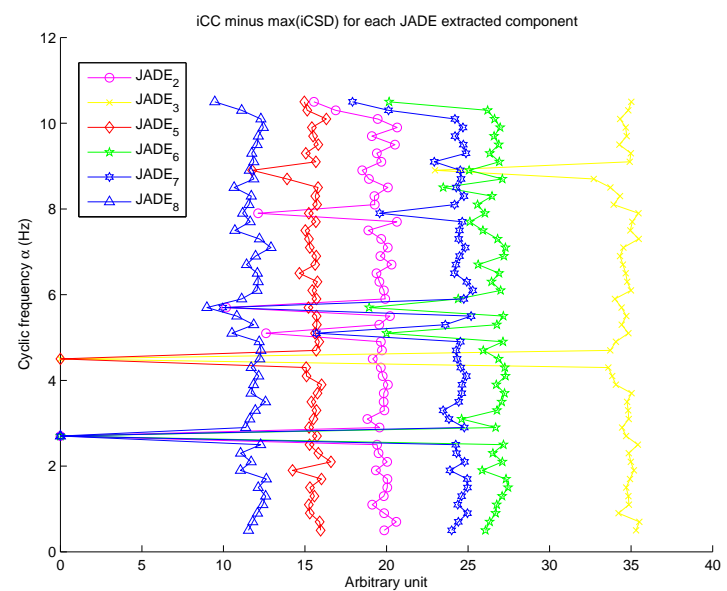

Fig. 5: The two null values of the remaining 6 transformed iCCs do correspond to the FECG's and the MECG's fundamental cyclic frequencies $(4.5 \mathrm{~Hz}$ and $2.7 \mathrm{~Hz}$, respectively)

Then, from each one of the previously computed iCCs, one subtracts its maximum value as shown in Figure 5. This is implemented only for extracted components that they do not span the noise subspace, i.e., JADE extracted components $\{2,3,5,6,7,8\}$. One remarks that the yellow $\left(J A D E_{3}\right)$ and red $\left(J A D E_{5}\right)$ data plots of Figure 5 exhibit both a null value for the same cyclic frequency equal to $4.5 \mathrm{~Hz}$ (i.e., the foetus' heart cyclic frequency) while the four remaining components have a modified iCC of zero value at $2.7 \mathrm{~Hz}$ (i.e., the mother's heart cyclic frequency). Finally, one can group blind-separated ICs into 3 independent subspaces: the FECG one spanned by ICs $\{3,5\}$, a noise one spanned by ICs $\{1,4\}$ and the MECG subspace spanned by ICs $\{2,6,7,8\}$.

\section{CONCLUSION}

This work proposes an automated classification procedure of blindly separated independent foetal components from maternal ECG recordings, that consists of four steps:

1. Apply a BSS/ICA algorithm to extract ICs from raw ECG data.

2. Compute the $\mathrm{CC}$ and then the iCC for each extracted independent component at the previous step.

3. Classify ICs whose standard deviation value of their iCC is below a threshold into a subspace corresponding to the noise.

4. Compute the difference between each iCC and its maximum value, and group into the same independent source subspaces the corresponding ICs exhibiting null values for the same cyclic frequencies.

The method is tested on the real world DaISy dataset and gave very promising results. Future research work concerns the validation of this method to simulated foetal ECGs, as well as further investigations about the computed CCs of the MECG source subspace components.

\section{ACKNOWLEDGEMENTS}

A. K. Nandi would like to thank the Université d'Orléans for the Visiting Professorship, which contributed to this study.

\section{REFERENCES}

1. Zarzoso V, Nandi A K. Noninvasive Foetal Electrocardiogram Extraction: Blind Separation Versus Adaptive Noise Cancellation IEEE Transactions on Biomedical Engineering. 2001;48(1):12-18.

2. Sameni R, Jutten C, Shamsollahi M B. Multichannel Electrocardiogram Decomposition Using Periodic Component Analysis IEEE Transactions on Biomedical Engineering. 2008;55(8):1935-1940.

3. Martín-Clemente R, Camargo-Olivares J L, Ornillo-Mellado S, Helena M, Román I. Fast Technique for Noninvasive Fetal ECG Extraction IEEE Transactions on Biomedical Engineering. 2001;58(2):227-230.

4. Herault J, Jutten C, Ans B. Détection de grandeurs primitives dans un message composite par une architecture neuromimétique en apprentissage non supervisé in Actes 10ème Colloque GRETSI(Nice, France): 1017-1022 1985.

5. Sameni R, Clifford G D. A Review of Fetal ECG Signal Processing Issues and Promising DIrections The Open Pacing, Electrophysiology \& Therapy journal. 2010;3:4-20.

6. Jutten C, Herault J. Blind separation of sources, part I: An adaptive algorithm based on neuromimetic architecture Signal Processing. 1991;24(1):1-10.

7. Jutten C, Herault J. Blind separation of sources, part II: Problems statement Signal Processing. 1991;24(1):11-20.

8. Comon P. Independent Component Analysis, a New Concept Signal Processing, Special Issue on Higher Order Statistics. 1994;36(3):287314.

9. Lathauwer L De, Moor B De, Vanderwalle J. Fetal Electrocardiogram Extraction by Source Subspace Separation in Proceedings IEEE Signal Processing / Athos Workshop on Higher-Order Statistics:134-138 1995.

10. Cardoso J F. Multidimensional independent component analysis in Proceedings of the 1998 IEEE International Conference on Acoustics, Speech and Signal Processing;4:1941-1944 1998.

11. Cardoso J F, Souloumiac A. Blind beamforming for non Gaussian signals in Radar and Signal Processing, IEE Proceedings F;140(6):3623701993.

12. Haritopoulos M, Capdessus C, Nandi A K. Foetal PQRST Extraction from ECG Recordings using Cyclostationary-Based Source Separation Method in 32 Annual International Conference of the IEEE EMBS:1910-1913 2010.

13. Max J, Lacoume J L. Méthodes et techniques de traitement du signal et application aux mesures physiques. Tome 1 : Principes généraux et méthodes classiques. fifth ed. 1996.

14. Hurd H L. An investigation of periodically correlated stochastic processes. PhD thesisDuke University 1970.

15. ESAT/SISTA K. U. Leuven. DaISy; Database for the Identification of Systems at http://homes.esat.kuleuven.be/ smc/daisy/ 1999. 